\title{
Endometriosis and the Urinary Tract: From Diagnosis to Surgical Treatment
}

\author{
Mathew Leonardi ${ }^{1,2,3, *}$, Mercedes Espada ${ }^{1,2}$, Rosanne M. Kho ${ }^{4}$, Javier F. Magrina ${ }^{5}$, \\ Anne-Elodie Millischer ${ }^{6}$, Luca Savelli ${ }^{7}$ and George Condous ${ }^{1,2}$
}

1 Acute Gynaecology, Early Pregnancy and Advanced Endoscopy Surgery Unit, Nepean Hospital, Kingswood, NSW 2747, Australia; medimer@hotmail.com (M.E.); georgecondous@omnigynaecare.com.au (G.C.)

2 Nepean Clinical School, University of Sydney, Sydney, NSW 2747, Australia

3 Endometriosis Clinic, Department of Obstetrics and Gynecology, McMaster University, Hamilton, ON L8N3Z5, Canada

4 Obstetrics, Gynecology, and Women's Health Institute, Cleveland Clinic, Cleveland, OH 44195, USA; sahnmd@gmail.com

5 Department of Medical and Surgical Gynecology, Mayo Clinic Hospital, Phoenix, AZ 85054, USA; jmagrina@mayo.edu

6 IMPC Radiology Bachaumont Paris and Radiodiagnostics Department, Hôpital Necker, 75015 Paris, France; aemillischer@gmail.com

7 Department of Obstetrics and Gynecology, S. Orsola Malpighi Hospital, University of Bologna, 40126 Bologna, Italy; luca.savelli@aosp.bo.it

* Correspondence: mathew.leonardi@sydney.edu.au

Received: 3 September 2020; Accepted: 29 September 2020; Published: 30 September 2020

\begin{abstract}
We aim to describe the diagnosis and surgical management of urinary tract endometriosis (UTE). We detail current diagnostic tools, including advanced transvaginal ultrasound, magnetic resonance imaging, and surgical diagnostic tools such as cystourethroscopy. While discussing surgical treatment options, we emphasize the importance of an interdisciplinary team for complex cases that involve the urinary tract. While bladder deep endometriosis (DE) is more straightforward in its surgical treatment, ureteral DE requires a high level of surgical skill. Specialists should be aware of the important entity of UTE, due to the serious health implications for women. When UTE exists, it is important to work within an interdisciplinary radiological and surgical team.
\end{abstract}

Keywords: endometriosis; ureter; bladder; ultrasound; magnetic resonance imaging; hydroureter

\section{Introduction}

Endometriosis is a chronic and benign condition thought to affect up to $10 \%$ of female-born individuals [1]. In most classic teachings, it causes cyclic pelvic pain and infertility. Other symptoms can include noncyclical pelvic pain, bloating, change in bowel habits, urinary tract symptoms, and fatigue. It was historically considered a gynecologic condition, managed by obstetrician-gynecologists. However, it is increasingly recognized that endometriosis is a multiorgan and systemic inflammatory disease that necessitates interdisciplinary care, led by a gynecologist with subspecialty training in clinical and surgical management [2,3]. Though its etiology remains partially shrouded, symptoms are caused by the presence of ectopic endometrial-like tissue outside of the uterus [4]. There are three broad phenotypes: superficial endometriosis (SE), ovarian endometriomas, and deep endometriosis (DE). The term urinary tract endometriosis (UTE) refers to endometriotic implants of the bladder, ureter, kidney, and urethra. The bladder and ureter are most commonly affected [5]. This paper will 
review the epidemiology, pathogenesis, clinical presentation, diagnosis and differential diagnosis, with emphasis on the imaging and management of UTE.

\section{Epidemiology of UTE}

The prevalence of UTE in the general female-born population remains unclear, since around $50 \%$ of women with UTE may be asymptomatic [6]. UTE most commonly affects the bladder [7]. The prevalence of UTE, from studies done in Europe, is estimated to range from 0.3 to $12 \%$ of all people affected by endometriosis and about $20-52.6 \%$ of women with deep endometriosis (DE) [8,9]. The urinary system is the second most common site of extrapelvic endometriosis after the gastrointestinal tract [10]. The prevalence of disease at specific sites among women with UTE is as follows: bladder, $85 \%$; ureter, $10 \%$; kidney, $4 \%$; and urethra, $2 \%$ [5].

\section{Pathogenesis of UTE}

The two phenotypes of UTE are superficial endometriosis (SE) and deep endometriosis (DE) [11]. SE can be recognized with a laparoscopy as black, white, or red implants, depending on the degree of fibrosis, scarring, and hemorrhage within the tissue. DE is defined by the invasion of endometrial-like glands and stroma at least $5 \mathrm{~mm}$ beneath the peritoneal surface. Deep implants are often associated with fibrosis and/or smooth muscle proliferation and are most frequently associated with pelvic pain and infertility [12].

General theories of endometriosis etiology include retrograde menstruation, coelomic metaplasia, spread of endometrium-derived stem/progenitor cells, and altered genetic/epigenetic or immune factors [13]. Additionally, in some women UTE appears to be iatrogenic; bladder endometriosis may be more prevalent amongst women with previous Caesarean section(s) [14].

Certain anatomic structures of the female pelvis are thought to provide secluded peritoneal pockets that provide protection to the ectopic endometrial-like cells from the regular peritoneal clearance mechanisms, allowing those cells to implant, invade, and proliferate [15]. This sanctuary effect may explain why women with retroverted uteruses are less prone to develop bladder endometriosis, or why ureteral endometriosis is more common on the left side [16].

\section{Bladder Endometriosis}

\subsection{Definition of Bladder Endometriosis}

Bladder DE is defined by the presence of endometriotic tissue invading the detrusor muscle of the bladder. The invasion of the detrusor muscle can be either full thickness or partial thickness [15]. Bladder DE most commonly develops in the bladder base and bladder dome, rather than in the extra-abdominal bladder [17]. The demarcation point between the base and the dome of the bladder is the vesicouterine pouch (Figure 1). 


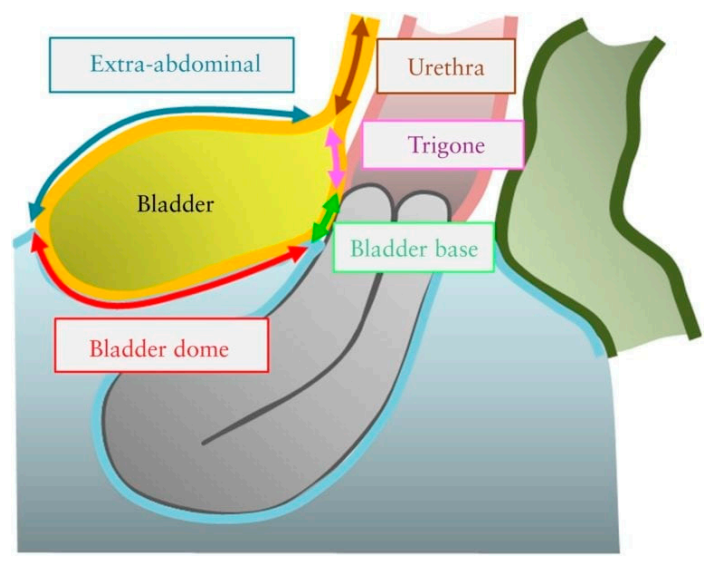

Figure 1. Schematic drawing illustrating the four bladder zones: trigone, bladder base, bladder dome, and extra-abdominal bladder. The demarcation point between the base and the dome of the bladder is the uterovesical pouch. Reprinted with permission from John Wiley and Sons.

\subsection{Clinical Symptoms of Bladder DE}

Endometriosis classically causes cyclic pain and infertility. Typically, women with bladder DE present with dysuria [10] but may also have urinary frequency, recurrent urinary tract infections $[10,18]$ and hematuria, and, more atypically, urinary incontinence [18]. Bladder endometriosis can also be asymptomatic and incidentally diagnosed at the time of a cystoscopic or intra-abdominal procedure for a different indication. As far as we are aware, the frequency of incidental diagnoses of bladder endometriosis is still unknown.

\subsection{Diagnosis of Bladder DE}

Bladder DE is a histologic diagnosis. The initial evaluation of suspected bladder endometriosis includes the medical history, a physical examination, and complementary tests (laboratory testing, cystourethroscopy, and imaging techniques).

\subsubsection{Medical History and Physical Examination}

Women with bladder endometriosis often have endometriosis at other anatomic sites; therefore, the initial history and physical assessment include speculum examination (looking for lesions on the posterior cervix or vaginal mucosa), tenderness on vaginal examination, nodules in the posterior vaginal fornix, adnexal masses, and immobility or lateral displacement of the uterus.

\subsubsection{Laboratory Testing}

For women with clinical symptoms of bladder DE (dysuria, urinary frequency, hematuria), a urinalysis test to exclude infection or hematuria should be conducted. If infection is suspected, a urinary culture should also be done. Women with hematuria and suspected bladder endometriosis should receive further testing.

\subsubsection{Imaging Techniques}

\section{Ultrasound}

Ultrasound is the first-line imaging modality for diagnosing or excluding BE and should be performed transvaginally. Transabdominal ultrasound is also important for renal assessments. The International Deep Endometriosis Analysis (IDEA) group recommends a focused assessment of the bladder and ureters (in addition to a thorough examination for other sites of DE, ovarian endometriomas, and pelvic adhesions, as depicted by the immobility of pelvic organs) [17]. It is important to note that the components of this ultrasound examination exceed those of the traditional, 
basic pelvic ultrasound [19], which does not include a direct evaluation of DE [17] or dynamic pelvic organ mobility as a soft marker for DE [20,21]. Patients should be sent to the closest radiologist or sonologist with expertise in endometriosis, with a requisition that specifies the need to evaluate the bladder wall and ureteral size and position. Even in centers of expertise, ultrasound is imperfect, with the possibility of false negatives and false positives, which in the case of false negatives is related to the size of a nodule, where smaller nodules are more likely missed [22]. False positives are exquisitely rare, and, in fact, none were detected as per Savelli et al. in a diagnostic accuracy study on bladder endometriosis [22]. For the transvaginal ultrasound (TVS) evaluation of the bladder, a small amount of urine in the bladder is helpful in order to better identify the different portions of the bladder wall. We recommend placing the TVS probe in the anterior vaginal fornix and gently swinging it side-to-side, visualizing the mucosa and muscularis for focal thickening and for hypoechoic linear or nodular lesions (either spherical or comma-shaped) (Figure 2, Supplementary Video S1) [22]. Figure 3 is a sonographic image with an overlying graphic depiction of abnormality and boundaries. Bladder nodules must be measured in three orthogonal planes [17]. Measuring the distance between the lesion and ureteral orifices may assist in surgical planning.

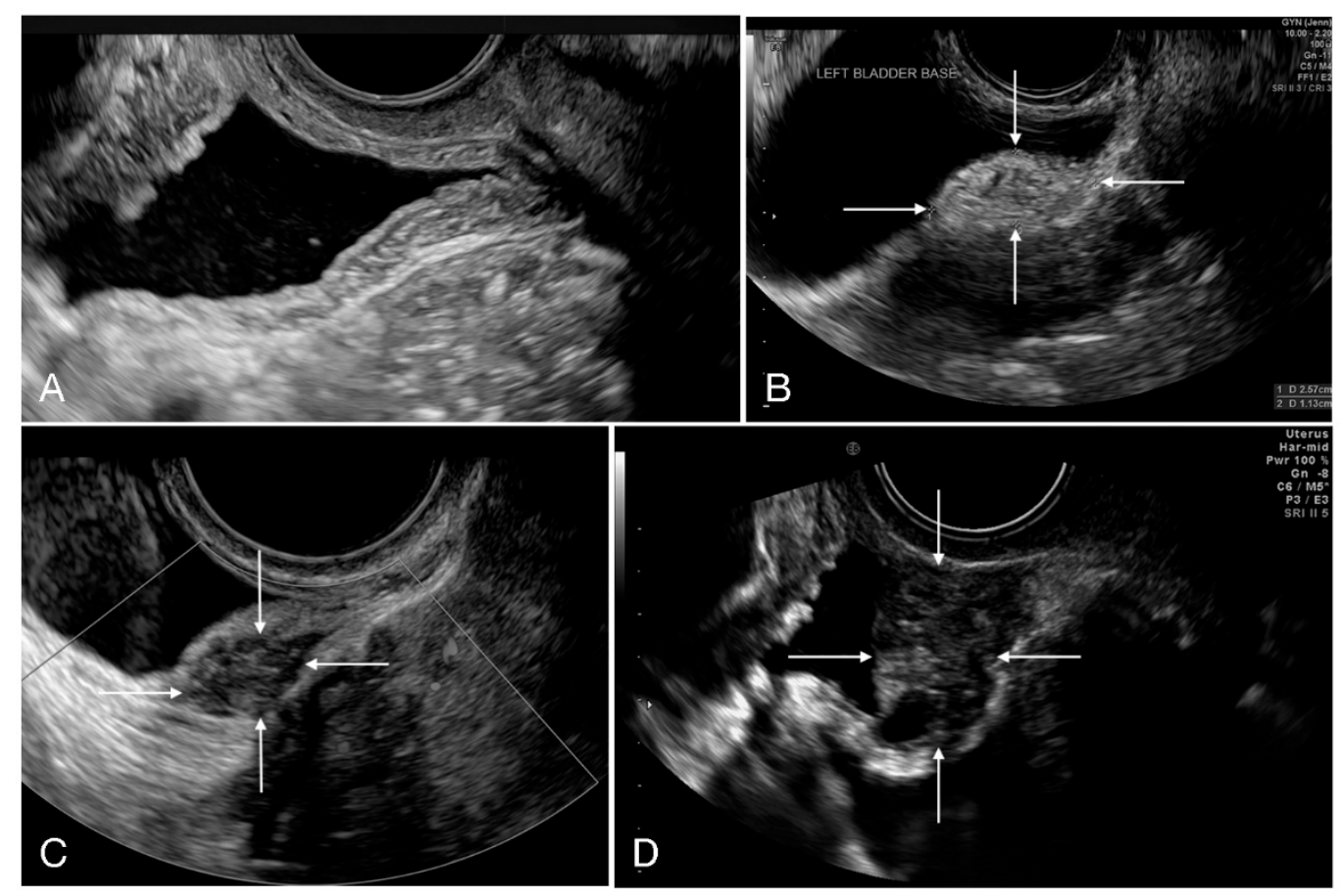

Figure 2. Transvaginal ultrasound depiction of the bladder. (A) Normal bladder and (B-D) three bladder deep endometriosis nodules, identified with white arrows. 


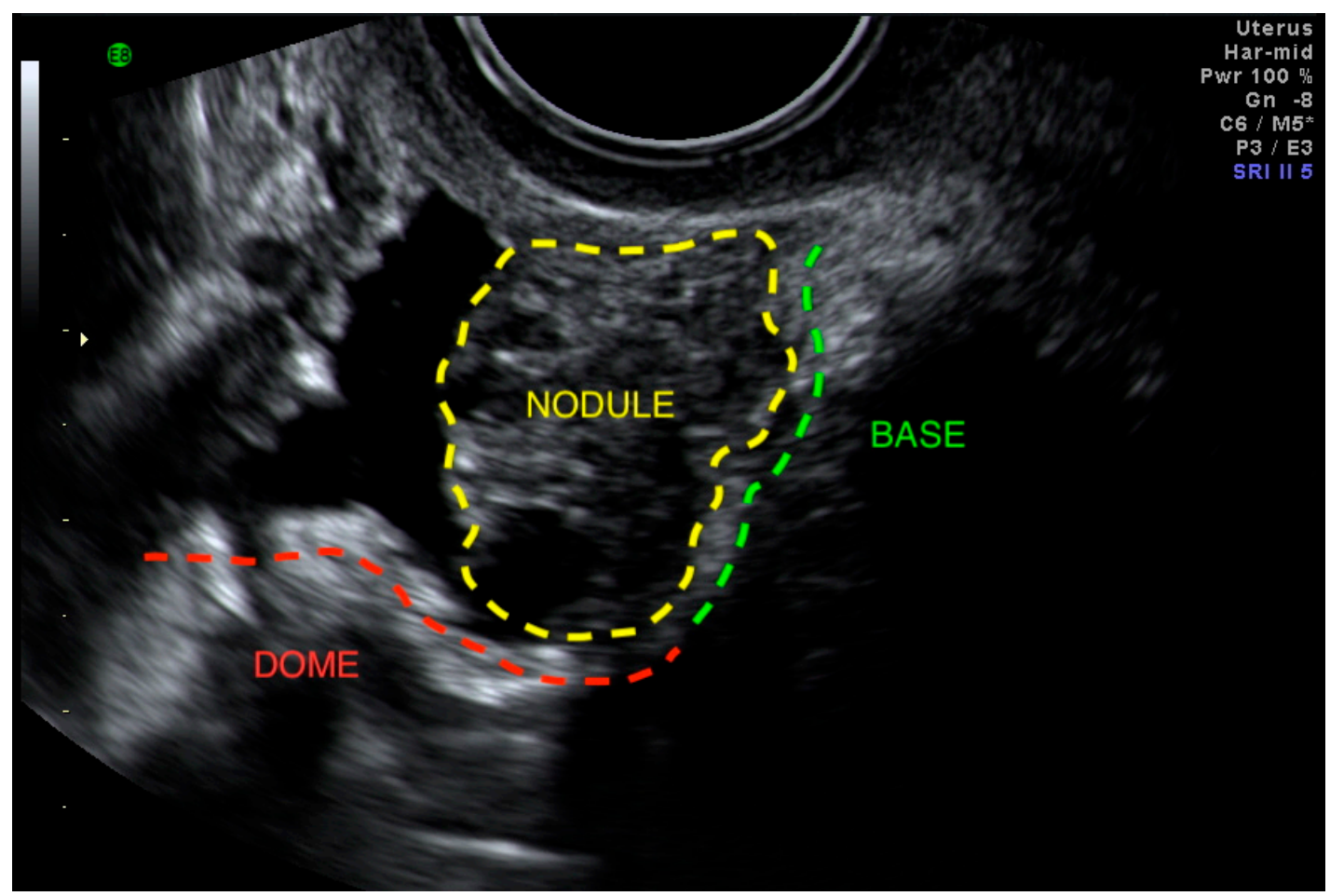

Figure 3. Bladder base deep endometriosis nodule encroaching on the bladder dome.

The pelvic segment of the ureters can be examined next by moving the TVS probe from the midline toward the pelvic sidewalls. Operators should search for a long tubular hypoechoic structure with a thick hyperechoic outer wall extending from the lateral aspect of the bladder base towards the common iliac vessels [23]. Vermiculation and/or the absence of color Doppler within the tubular structure can be used to confirm that it is a ureter rather than a vessel. The goal is to then follow the ureter as proximally as possible, in the direction of its origin, assessing for dilatation, position, any asymmetry between the right and left side, and eventually the presence of DE nodules, which appear as hypoechoic lesions around the course of the ureter (Figure 4). The presence of ureteral jets (i.e., the urinary inflow from the ureter into the bladder) can be seen using color Doppler after waiting for a few seconds/minutes [22]. In an observational study, Carfagna et al. found that the ureteric diameter on TVS was $\geq 6 \mathrm{~mm}$ with a median diameter of $6.9 \mathrm{~mm}$ (range, $6-18 \mathrm{~mm}$ ) in all cases of ureteral dilatation confirmed at surgery [24]. Nodules of the USL with or without parametrial infiltration must be assessed [25] with measurements in three orthogonal planes [26]. Nodules $\geq 17 \mathrm{~mm}$ should, in particular, raise suspicion for ureteral involvement [27]. 


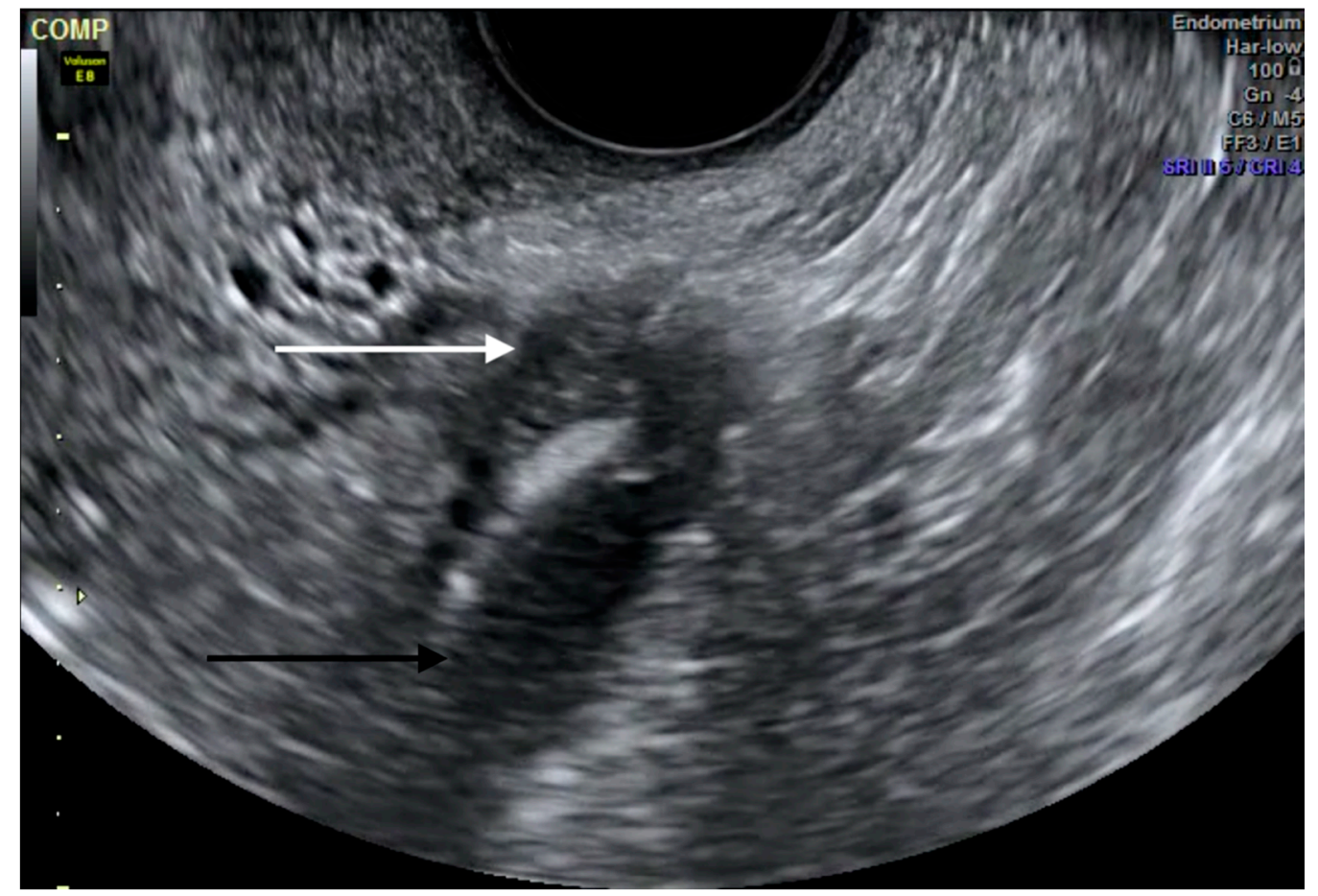

Figure 4. Transvaginal ultrasound depiction of ureteral deep endometriosis nodule (white arrow) and hydroureter (black arrow). The nodule originates from the uterosacral ligament but infiltrates the parametrium and extrinsically compresses the ureter.

A transabdominal scan (TAS) of the kidneys is recommended in all women with concerns for UTE in order to exclude the presence of hydronephrosis, as this is usually asymptomatic in cases of ureteral DE [28,29].

\section{Magnetic Resonance Imaging}

Magnetic resonance imaging (MRI) is an adjunct imaging tool that can be considered as completing or supplementing TVS for an accurate presurgical staging of UTE. Though a recent study did not identify an added value from MRI after TVS for overall endometriosis [30], a small retrospective diagnostic accuracy study did show MRI as having greater sensitivity than TVS for bladder DE [31]. As such, MRI may be most appropriate in centers where advanced TVS for UTE is not yet available or where TVS is negative and there is a high clinical suspicion of bladder DE.

The diagnosis of bladder DE is based on a hypointense signal of nodules on T2-weighted images with a frequent hyperintense signal on fatty saturation T1-weighted images. The nodule is usually located at the level of the vesicouterine pouch within the bladder base, forming an obtuse angle with the bladder wall and involving the muscularis layer (depicted by an obliteration of the hypointense signal of the wall on T2-weighted MR images (Figure 5)), or protruding into the lumen with invasion of the mucosal layer [32]. Retrospective and recent studies suggest that MRI is particularly relevant for diagnosing bladder endometriosis, with an accuracy of $96 \%$ [31], and with a sensitivity and specificity ranging from $88 \%$ to $100 \%$ and from $98 \%$ to $100 \%$, respectively [31,32], whereas meta-analyses by Medeiros et al. [33] and Nisenblat et al. [34] reported sensitivities of $64 \%$ and $41 \%$, respectively. 


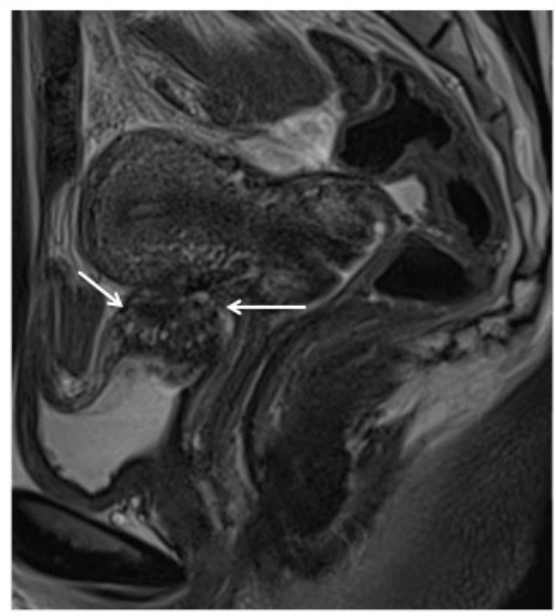

Figure 5. Magnetic resonance imaging depiction of bladder deep endometriosis. Sagittal T2-weighted plane depicting deep endometriosis nodule in hyposignalT2, which is infiltrating the detrusor muscle of the bladder (white thin arrows).

Ureteral endometriosis typically appears as a nodule at a low-intensity signal in T2-weighted sequences (Figure 6), associated with retractile adhesions on surrounding fatty tissue [35]. The reliability of MRI to differentiate an extrinsic or intrinsic involvement is limited and discussed in the literature [35]. However, two features may be useful in identifying intrinsic DE: a degree of sheathing of the ureter at more than 180 degrees [36] and a loss of the fatty interface [37], even if this tends to overestimate the frequency of intrinsic disease. MRI demonstrates a sensitivity of $91 \%$ and a specificity of $59 \%$, in comparison to the performance of laparoscopy as a diagnostic tool, which has a sensitivity of $82 \%$ and a specificity of $67 \%$. It is interesting, though not surprising, that MRI is more sensitive than surgery considering the severe anatomic distortion, which limits the visibility of the disease location and extent via a direct visualization at surgery [38]. Ureteral dilatation is suggestive of a diagnosis of parametrial endometriosis and can be emphasized by the use of MR urography [39].
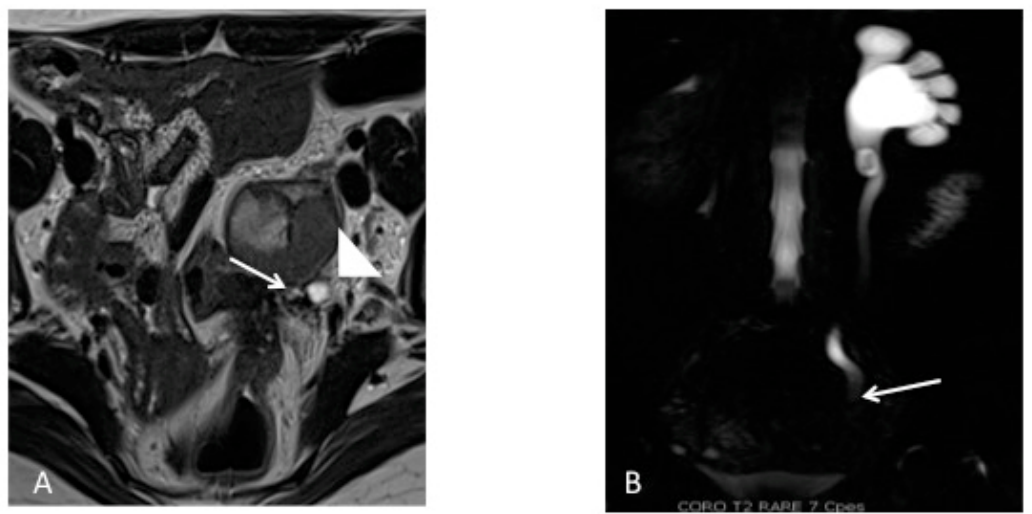

Figure 6. Magnetic resonance imaging depiction of left ureteral deep endometriosis. (A) Axial T2-weighted plane depicting hyposignal nodule causing stenosis of the left ureter (white arrows), which appears dilated and is confirmed on the (B) magnetic resonance urography in the coronal HASTE T2 plane.

Supplementary Imaging

A transabdominal scan (TAS) of the kidneys is recommended in all women with concerns for UTE in order to exclude the presence of hydronephrosis, as this is usually asymptomatic in cases of ureteral DE [28,29]. For women with bladder lesions on TVS and asymmetrical ureteral caliber or hydronephrosis, a computed tomography (CT) urogram, which utilizes contrast, may be useful 
in completing the evaluation because CT best depicts the course of the ureters. CT is not used as a supplement to diagnose bladder DE. Transrectal ultrasound is possible and utilized for endometriosis diagnosis, but is likely less useful for anterior compartment disease for obvious reasons of probe positioning. It could be considered for those who cannot undergo a TVS, but MRI would be preferable in these cases.

\section{Cystourethroscopy}

When there is proven hematuria or a bladder nodule visible on TVS or MRI, we find that performing a cystourethroscopy may be helpful to confirm the diagnosis. Cystoscopically, BE can have a spectrum of possible appearances from normal-appearing mucosa that is noticeably raised due to a nodule beneath the mucosa to infiltration through the mucosa. In the latter scenario, lesions can appear to be multiloculated with a combination of colors (from the same color as the bladder mucosa to a blue/violet color) [40]. Cystourethroscopy can also aid in excluding malignancies and in measuring the distance from the lesion to the ureteral openings to help urologists and gynecologists anticipate the type of urologic procedure necessary (particularly if the removal of the lesion will also require ureteral resection and reimplantation with ureteroneocystostomy) [41,42]. If the distance between the edge of the endometriotic lesion and the interureteric ridge is less than $2 \mathrm{~cm}$, ureteroneocystostomy is typically performed in order to reduce the risk of ureteral obstruction and fistula formation [5], and in order to optimally restore a normal anatomy.

\subsection{Differential Diagnosis of Bladder DE}

\subsubsection{Intraluminal Bladder Lesions}

Angiomas and papillomas can be diagnosed by a guided tissue sampling with cystoscopy. It is especially important to rule out bladder neoplasms, as they can mimic endometriosis symptoms and a false diagnosis of endometriosis may lead to poorer outcomes [43].

\subsubsection{Urinary Tract Infection}

This can be excluded with a urine culture test.

\subsubsection{Urinary Tract Calculus}

The type of pelvic pain associated with urinary tract calculus is variable in severity and duration, whereas the pain associated with bladder DE is consistent. Urinary tract calculus can be identified in ultrasound studies as mobile and echogenic formations with associated acoustic shadowing. They can be associated with bladder wall thickening due to inflammation [5].

\subsubsection{Interstitial Cystitis}

Interstitial cystitis is a clinical diagnosis that involves bladder discomfort associated with bladder repletion. This is a diagnosis of exclusion that can only be reached when other etiologies, such as malignancy or bladder DE, have been ruled out.

\subsection{Treatment of Bladder DE}

The aim of the treatment of bladder DE is to resolve symptoms and avoid possible renal damage. Treatment can be expectant, medical, or surgical. A conservative management with a sonographic follow-up can be chosen for asymptomatic women without hydronephrosis, while surgery should always be performed in women with ureteral obstruction and hydronephrosis. Pain symptoms can be managed medically or surgically. 


\subsubsection{Medical Management}

For patients with pain symptoms due to bladder DE, continuous progesterone-based regimens (pills, intrauterine device, implant, injection), combined estrogen-progesterone therapy (continuous or sequential regimens), and GnRH analogues (with or without add-back therapy) have all been associated with an improvement of symptoms from bladder DE [44,45].

Women who respond to medical management can continue the treatment until menopause or until the desire to conceive from pregnancy or to achieve an optimal quality of life and reduce the risk of progression, unless there is superimposed hydronephrosis, in which instance surgery would be the first treatment choice to prevent irreversible renal failure from ureteral obstruction.

\subsubsection{Surgical Management}

Procedures to surgically address bladder DE include the shaving of serosal lesions and full thickness resection of DE lesions. Most surgeries can be performed laparoscopically or robotically [44].

\subsubsection{Surgical Approach}

(1) Cystourethroscopy: to evaluate the size of the lesion(s) and measure the distance between the lesion and the ureteral ridge. The use of ureteral catheters is not supported by strong evidence-based data; however, their use might be helpful when the distance between the lesion and the ureteral ridge is less than $2 \mathrm{~cm}$ or when the anatomy is distorted from previous surgeries or extensive disease, in order to reduce the risk of inadvertent ureteral damage at surgery.

(2) Diagnostic laparoscopy, followed by the shaving of superficial serosal lesions off the bladder or partial cystectomy (Figure 7) when there is infiltration of the detrusor muscle, in order to restore a normal anatomy and prevent hydronephrosis and recurrence of the disease [6]. If the nodule affects the vesical base, it can either be approached laparoscopically (starting with the dissection of the vesicouterine pouch to facilitate a complete resection) or through an operative cystoscope, followed by reconstruction of the bladder either laparoscopically or robotically. Resecting the underlying myometrium has been proven to prevent a recurrence of the symptoms when it comes to bladder DE affecting the vesical base [46].

(3) Bladder closure: We recommend closing the bladder with two layers of transverse sutures. At the end of the operation, the bladder is filled with methylene blue to confirm the integrity of the bladder, and a bladder catheter should be left in place for 10 days to prevent fistula formation.

Surgical resection of bladder endometriosis is a risk factor for fistula formation (up to $15 \%$ of patients) [47].

\subsubsection{Medical versus Surgical Treatment}

There are limited data comparing the surgical and medical approach to bladder DE. On this basis, we would recommend to start on a trial of COCP, progesterone, or GnRH analogues (with or without add-back therapy) for six months for women with symptomatic bladder DE who do not have associated hydronephrosis, and to reserve the surgical approach to patients who either do not respond to medical treatment or who have hydronephrosis [6,44-47]. 


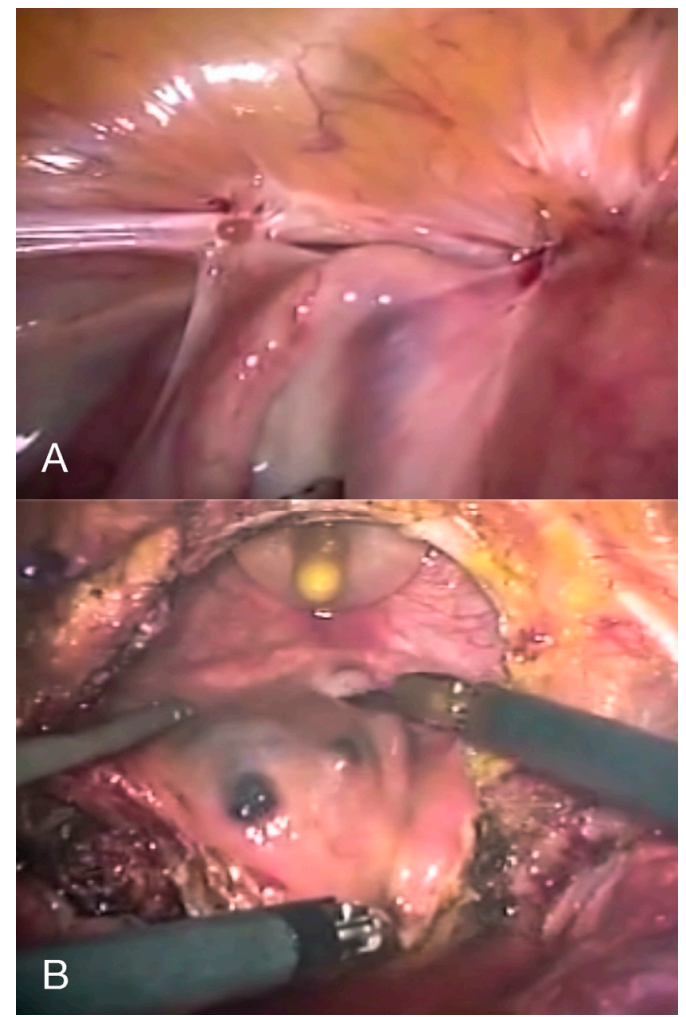

Figure 7. Laparoscopic depiction of bladder deep endometriosis (A) before and (B) during full-thickness resection.

\section{Ureteral Endometriosis}

\subsection{Definition of Ureteral Endometriosis (UE)}

Ureteral endometriosis (UE) is defined by the presence of endometriotic tissue involving the ureter. UE can be further subclassified as intrinsic, consisting of $40 \%$ of lesions when endometriosis develops within the ureteral wall, resulting in fibrosis and hypertrophy of the muscularis propria, and extrinsic, consisting of $60 \%$ of the lesions when the endometriosis develops primarily out of the ureteral wall and causes compression from the outside [48]. Though the parametrium is the main site of endometriosis that leads to extrinsic ureteral compression, it is thought that many of these nodules originate from the anterior rectal wall or uterosacral ligaments (USLs) DE [38].

\subsection{Clinical Symptoms of UE}

Patients with UE generally have nonspecific symptoms. It is estimated that $50 \%$ of women with UE are asymptomatic, $25 \%$ present with flank pain, and 15\% have associated gross hematuria [49-51]. Other concomitant symptoms associated with UE include dysmenorrhea and deep dyspareunia [52].

\subsection{Diagnosis of UE}

Tissue biopsy and histologic confirmation is the gold standard for diagnosing UE [52]. The initial evaluation of suspected UE includes a detailed medical history, physical examination, and complementary tests (laboratory testing, cystourethroscopy, and imaging techniques)

\subsubsection{Medical History and Physical Examination}

UE is often associated with extensive pelvic disease, and therefore the initial history and physical assessment are key and should include a speculum examination (looking for lesions on the posterior 
cervix or vaginal mucosa), tenderness on vaginal examination, nodules in the posterior vaginal fornix, adnexal masses, and immobility or lateral placement of the uterus [52].

\subsubsection{Laboratory Testing}

It is important to exclude impaired renal function when there is suspected UE. Renal function tests and urinalysis, to include infection, should be conducted in patients with flank pain or hematuria [53].

\subsubsection{Imaging Techniques}

TAS can help to detect ureteral obstruction and evaluate the thickness of the renal parenchyma. TVS can only assess the pelvic ureter, but it is very useful for evaluating other sites of implants of endometriosis in the pelvis [17]. Combined TAS/TVS should be performed as a first-line exam when suspecting UE. By doing combined TAS/TVS, the ureters can be visualized from the anterior parametrium to the renal pelvis [54].

When there is associated hydroureter or hydronephrosis (Figure 4), additional radiologic studies such as MRI (Figure 5), CT and intravenous pyelography can help identify the sites of stenosis and assist with surgical planning. Women with suspected ureteral endometriosis should also be evaluated for bladder DE.

\subsection{Differential Diagnosis of UE}

For women with asymptomatic UE and hydronephrosis, other causes of acute or chronic kidney obstruction or injury should be excluded, particularly neoplasms. Women presenting with flank pain or hematuria should be tested to exclude urinary tract infection, urinary calculi, and neoplasms.

\subsection{Treatment of $U E$}

Since medical treatment does not necessarily revert the fibrotic component of UE yielding ureteral obstruction, surgical treatment of both extrinsic and intrinsic UE is generally necessary [55]. However, in the absence of obstruction, medical management can be considered, if desired by the patients, to reduce the risks associated with surgery.

The surgical treatment of UE aims at relieving ureteral obstruction and avoiding recurrence and reobstruction. The surgical approach depends on the symptoms, types of eventual previous surgery for UE, location of DE, the extent of compression, and the kidney function. Regardless of the planned procedure, ureteral catheters or stents can be used before surgically managing UE. In women with severe stenosis, they may have a preoperative placement of a ureteral pigtail stent to limit the ongoing loss of kidney function. For those where there is no concern of a kidney function loss, ureteral catheters or stents may be placed intraoperatively.

The surgical management of UE includes conservative ureterolysis with the removal of the adjacent $\mathrm{DE}$, or radical approaches such as ureterectomy with end-to-end anastomosis, ureteroneocystostomy, or nephroureterectomy. There is a lack of prospective randomized trials, given the low incidence of $\mathrm{UE}$, and most of the studies regarding the surgical management of UE are retrospective. In general terms, the surgical choice depends on the renal function and the extension of the ureteral segment (or segments) involved.

\subsubsection{Ureterolysis}

Any ureter affected by DE (USL/parametrial or peritoneal) will first require a ureterolysis (Figure 8) [56]. Coexisting DE in the posterior compartment may involve the bowel, torus uterinus, posterior vaginal fornix, or rectovaginal septum. In many cases, rectouterine pouch obliteration will exist, and the normalization of the anatomy must be an early surgical priority with the identification of the hypogastric nerves. As the approach to normalizing the distorted anatomy should start retroperitoneally, ureterolysis is often one of the first steps of the procedure. This is also important 
because the identification of the ureter course, which is often altered with posterior compartment DE, should lead to a reduction in the rate of ureteral injury. Identification of the hypogastric nerves, as they branch from the superior hypogastric nerve plexus, allows for a nerve-sparing procedure to preserve the patient's bladder, bowel, and sexual functions.

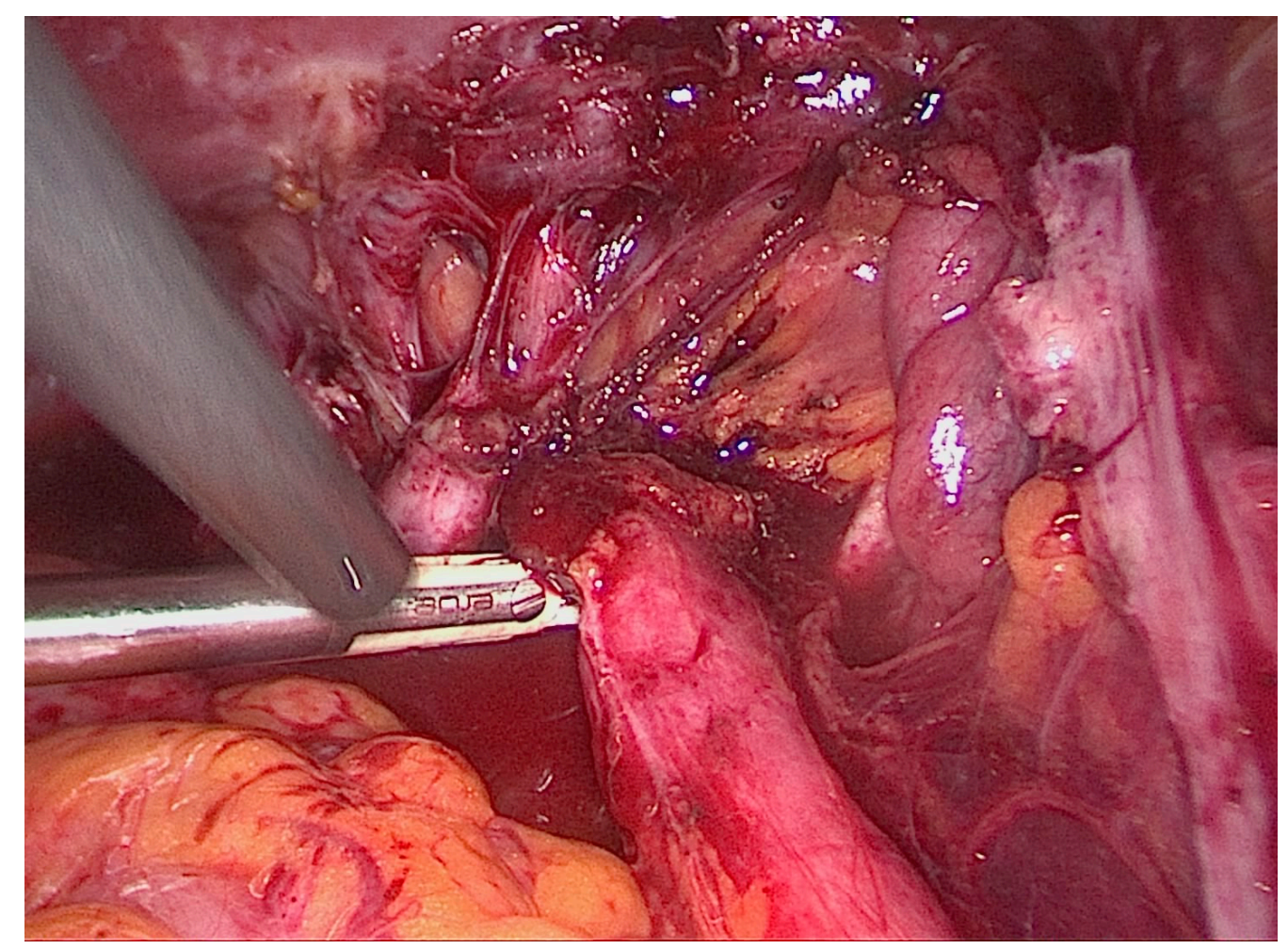

Figure 8. Laparoscopic depiction of right ureteral deep endometriosis leading to hydroureter.

Ureterolysis alone is indicated for minimal, extrinsic, and nonobstructive UE and is contraindicated in patients who have a complete ureteral obstruction [38]. Excision of surrounding endometriosis is recommended over ablation because ablation increases the risks of ureteral thermal injury, further obstruction, and fistula.

\subsubsection{Ureterolysis, Ureterectomy with Ureteroureteral Anastomosis}

This the procedure of choice for middle or upper third UE.

\subsubsection{Ureterolysis, Ureterectomy, and Ureteroneocystostomy}

This is, in general terms, the procedure of choice for distal third UE. After transection of the ureter proximal to the stricture, it is generally reimplanted in the bladder dome, with or without a bladder-psoas hitch, in order to achieve a tension-free anastomosis with antireflux plasty of the bladder valve (Figure 9) $[57,58]$.

\subsection{Postoperative Complications}

It is commonly thought that the risks of surgery are higher when a patient has endometriosis, but this is based on general (and often retrospective) gynecologic surgery literature. For example, the odds ratio of a genitourinary injury during hysterectomy for a benign indication was 1.46 (95\% confidence interval 1.36-1.56) when endometriosis was present [59]. There is less literature on the complication rate amongst those who undergo a combined gynecologic-urologic surgery for endometriosis with a thorough interdisciplinary evaluation, including preoperative imaging. It is currently thought that 
the cumulative surgical complication rate for patients surgically treated for UE is estimated to be $9 \%$. Major complications included the recurrence of ureteral obstruction $(7.4 \%)$, ureteral or ureterovaginal fistula (1.6\%), and hemoperitoneum (0.4\%) [5].

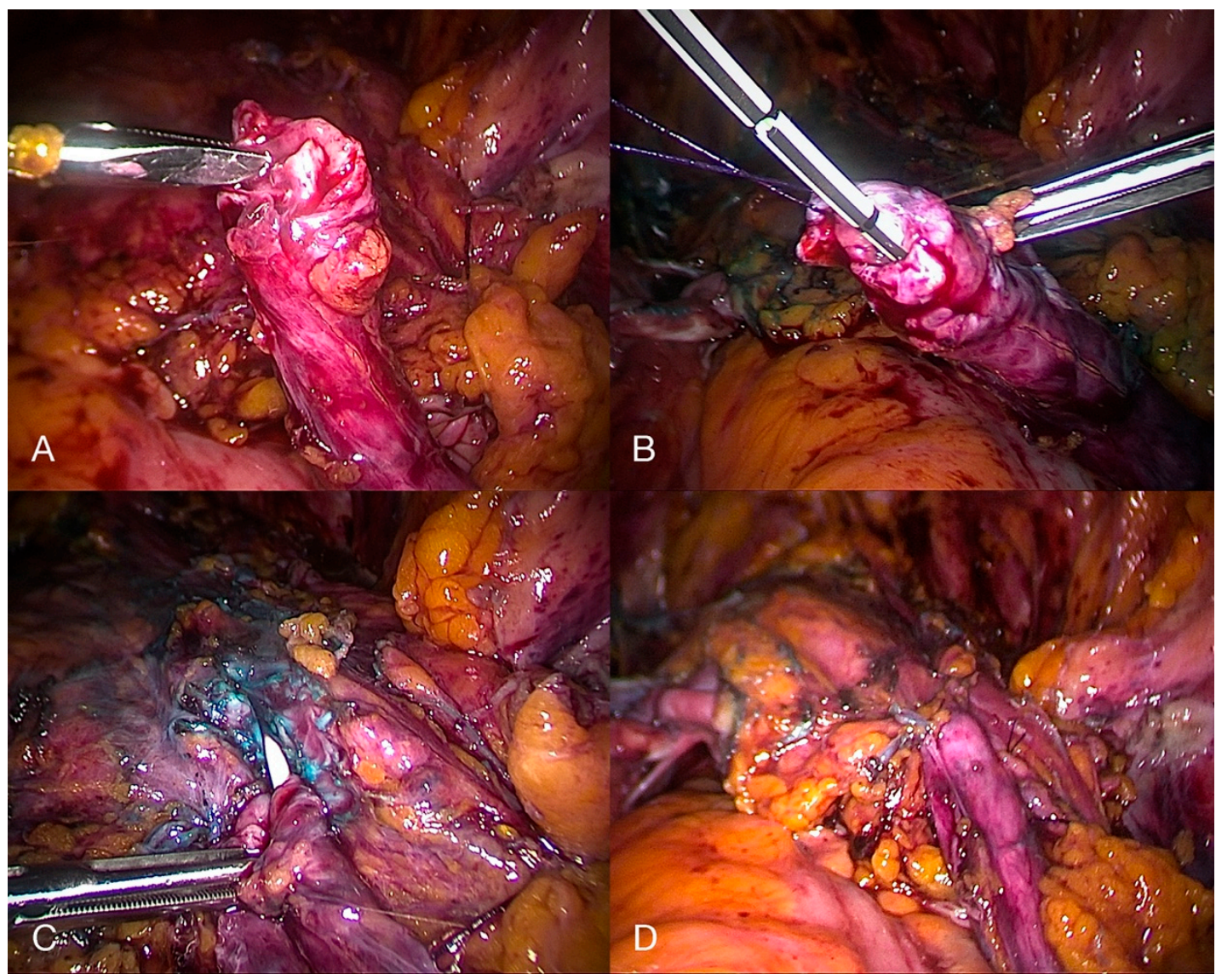

Figure 9. Laparoscopic depiction of a transected ureter (A) without stent and (B) with stent, followed by an (C) initial and (D) complete ureteroneocystostomy secondary to ureteral deep endometriosis.

Ceccaroni et al. have recently published a study on a series of 160 patients who underwent a laparoscopic excision of endometriosis and a ureteroneocystostomy $(75.6 \%$ also underwent a concurrent bowel resection), performed by an interdisciplinary team including urologists and colorectal surgeons [57]. They reported that seven patients underwent reoperation (4.4\%), eight experienced fever $(5 \%)$, four required blood transfusion $(2.5 \%)$, three had intestinal fistulas $(1.9 \%)$, and 24 experienced impaired bladder voiding (15\%) after six months. Their inclusion criteria for ureteroneocystostomy included $\geq 1$ of the following: mild to severe hydronephrosis $(\geq 1 \mathrm{~cm})$ with or without radiologic evidence of a ureteral stricture, intraoperative detection of the impossibility of performing ureterolysis because of a macroscopic infiltration of endometriosis, and ureteral ischemia after extensive ureterolysis.

\section{Discussion}

Endometriosis is a complex and highly variable disease that still challenges medical practice. It is estimated that UTE affects up to $1 \%$ of women with pelvic endometriosis (most commonly bladder endometriosis), but its prevalence is as high as $20-50 \%$ for women with DE [6]. It is increasingly recognized that endometriosis is a multiorgan and systemic inflammatory disease that necessitates interdisciplinary care. The success of multidisciplinary teams in cancer care should encourage their uptake in benign but chronic conditions such as endometriosis [3]. 
Gynecologists and urologists alike should be aware that DE of the bladder and ureters can be visualized on either advanced TVS or MRI. Gynecologists with expertise in the surgical treatment of endometriosis are indispensable for complex cases that involve the urinary tract. While bladder $\mathrm{DE}$ is straightforward in its surgical treatment, ureteral DE may be treated with a variety of methods, but the approach should be guided by expert ultrasound/MRI, ancillary tests, and the surgical expertise of a urologist. Although surgical complications remain a reality due to the infiltrative and anatomic-distorting nature of endometriosis, these can be mitigated by an earlier recognition of UTE symptoms, comprehensive noninvasive imaging diagnoses, and a strong collaboration between minimally invasive gynecologists and urologists. UTE that is inadvertently encountered at surgery (whether for endometriosis or other indications) may be best left untreated until proper evaluation, interdisciplinary discussion, and informed consent with the patient occurs.

It is our conviction that formalized multidisciplinary preoperative diagnosis and surgical treatment in an endometriosis referral center led by a gynecologist with subspecialty training in clinical and surgical management $[2,3]$ is necessary in order to have a plan that achieves optimal outcomes and mitigates surgical complications for patients with suspected UTE.

Supplementary Materials: The following are available online at http://www.mdpi.com/2075-4418/10/10/771/s1, Video S1: Bladder deep endometriosis.

Funding: This research received no external funding.

Conflicts of Interest: The authors declare no conflict of interest.

\section{References}

1. Berveiller, P.; Ropert, S.; Mir, O.; Becker, C.M.; Missmer, S.A.; Zondervan, K.T. Endometriosis. N. Engl. J. Med. 2020, 383, 193-194. [CrossRef]

2. Johnson, N.P.; Hummelshoj, L.; Abrao, M.S.; Adamson, G.D.; Allaire, C.; Amelung, V.; Andersson, E.; Becker, C.; Ardal, K.B.B.; Bush, D.; et al. Consensus on current management of endometriosis. Hum. Reprod. 2013, 28, 1552-1568. [CrossRef]

3. Leonardi, M.; Lam, A.; Abrão, M.S.; Johnson, N.P.; Condous, G. Ignored Because It Is Benign—It Is Time to Treat Endometriosis as if It Were Cancer. J. Obstet. Gynaecol. Can. 2020, 42, 507-509. [CrossRef]

4. Johnson, N.P.; Hummelshoj, L.; Adamson, G.D.; Keckstein, J.; Taylor, H.S.; Abrao, M.S.; Bush, D.; Kiesel, L.; Tamimi, R.; Sharpe-Timms, K.L.; et al. World Endometriosis Society consensus on the classification of endometriosis. Hum. Reprod. 2016, 32, 315-324. [CrossRef]

5. Berlanda, N.; Vercellini, P.; Carmignani, L.; Aimi, G.; Amicarelli, F.; Fedele, L. Ureteral and Vesical Endometriosis. Obstet. Gynecol. Surv. 2009, 64, 830-842. [CrossRef]

6. Seracchioli, R.; Mabrouk, M.; Montanari, G.; Manuzzi, L.; Concetti, S.; Venturoli, S. Conservative laparoscopic management of urinary tract endometriosis (UTE): Surgical outcome and long-term follow-up. Fertil. Steril. 2010, 94, 856-861. [CrossRef]

7. Maggiore, U.L.R.; Ferrero, S.; Candiani, M.; Somigliana, E.; Viganò, P.; Vercellini, P. Bladder Endometriosis: A Systematic Review of Pathogenesis, Diagnosis, Treatment, Impact on Fertility, and Risk of Malignant Transformation. Eur. Urol. 2017, 71, 790-807. [CrossRef] [PubMed]

8. Knabben, L.; Imboden, S.; Fellmann, B.; Nirgianakis, K.; Kuhn, A.; Mueller, M.D. Urinary tract endometriosis in patients with deep infiltrating endometriosis: Prevalence, symptoms, management, and proposal for a new clinical classification. Fertil. Steril. 2015, 103, 147-152. [CrossRef] [PubMed]

9. Gabriel, B.; Nassif, J.; Trompoukis, P.; Barata, S.; Wattiez, A. Prevalence and Management of Urinary Tract Endometriosis: A Clinical Case Series. Urology 2011, 78, 1269-1274. [CrossRef] [PubMed]

10. Maccagnano, C.; Pellucchi, F.; Rocchini, L.; Ghezzi, M.; Scattoni, V.; Montorsi, F.; Rigatti, P.; Colombo, R. Ureteral Endometriosis: Proposal for a Diagnostic and Therapeutic Algorithm with a Review of the Literature. Urol. Int. 2013, 91, 1-9. [CrossRef]

11. Espada, M.; Alvarez-Moreno, E.; De La Peña, M.J.; Capio, V.M.; Reid, S.; Condous, G. Imaging techniques in endometriosis. J. Endometr. Pelvic Pain Disord. 2018, 10, 136-150. [CrossRef] 
12. Koninckx, P.R.; Ussia, A.; Adamyan, L.; Wattiez, A.; Donnez, J. Deep endometriosis: Definition, diagnosis, and treatment. Fertil. Steril. 2012, 98, 564-571. [CrossRef]

13. Horne, A.W.; Saunders, P.T. SnapShot: Endometriosis. Cell 2019, 179, 1677-1677.e1. [CrossRef] [PubMed]

14. Somigliana, E.; Vercellini, P.; Gattei, U.; Chopin, N.; Chiodo, I.; Chapron, C. Bladder endometriosis: Getting closer and closer to the unifying metastatic hypothesis. Fertil. Steril. 2007, 87, 1287-1290. [CrossRef] [PubMed]

15. Fedele, L. Bladder Endometriosis: Deep Infiltrating Endometriosis or Adenomyosis? Fertil. Steril. 1998, 69, 972-975. [CrossRef]

16. Vercellini, P.; Pisacreta, A.; Pesole, A.; Vicentini, S.; Stellato, G.; Crosignani, P.G. Is ureteral endometriosis an asymmetric disease? BJOG: Int. J. Obstet. Gynaecol. 2000, 107, 559-561. [CrossRef]

17. Guerriero, S.; Condous, G.; Bosch, T.V.D.; Valentin, L.; Leone, F.P.G.; Van Schoubroeck, D.; Exacoustos, C.; Installé, A.J.F.; Martins, W.P.; Abrao, M.S.; et al. Systematic approach to sonographic evaluation of the pelvis in women with suspected endometriosis, including terms, definitions and measurements: A consensus opinion from the International Deep Endometriosis Analysis (IDEA) group. Ultrasound Obstet. Gynecol. 2016, 48, 318-332. [CrossRef]

18. Maggiore, U.L.R.; Ferrero, S.; Salvatore, S. Urinary incontinence and bladder endometriosis: Conservative management. Int. Urogynecol. J. 2014, 26, 159-162. [CrossRef]

19. Guideline developed in collaboration with the American College of Radiology (ACR); the American College of Obstetricians and Gynecologists (ACOG); (Spr), T.S.F.P.R.; (Sru), T.S.O.R.I.U. AIUM Practice Guideline for the Performance of Ultrasound of the Female Pelvis. J. Ultrasound Med. 2014, 33, 1122-1130. [CrossRef]

20. Arion, K.; Aksoy, T.; Allaire, C.; Noga, H.; Williams, C.; Bedaiwy, M.A.; Yong, P.J. Prediction of Pouch of Douglas Obliteration: Point-of-care Ultrasound Versus Pelvic Examination. J. Minim. Invasive Gynecol. 2019, 26, 928-934. [CrossRef]

21. Reid, S.; Leonardi, M.; Lu, C.; Condous, G. The association between ultrasound-based 'soft markers' and endometriosis type/location: A prospective observational study. Eur. J. Obstet. Gynecol. Reprod. Boil. 2019, 234, 171-178. [CrossRef] [PubMed]

22. Savelli, L.; Manuzzi, L.; Pollastri, P.; Mabrouk, M.; Seracchioli, R.; Venturoli, S. Diagnostic accuracy and potential limitations of transvaginal sonography for bladder endometriosis. Ultrasound Obstet. Gynecol. 2009, 34, 595-600. [CrossRef] [PubMed]

23. Bean, E.; Naftalin, J.; Jurkovic, D. How to assess the ureters during pelvic ultrasound. Ultrasound Obstet. Gynecol. 2019, 53, 729-733. [CrossRef] [PubMed]

24. Carfagna, P.; Nardone, C.D.C.; Nardone, A.D.C.; Scambia, G.; Marana, R.; Nardone, F.D.C.; Testa, A.C. Role of transvaginal ultrasound in evaluation of ureteral involvement in deep infiltrating endometriosis. Ultrasound Obstet. Gynecol. 2018, 51, 550-555. [CrossRef] [PubMed]

25. Leonardi, M.; Martins, W.P.; Espada, M.; Arianayagam, M.; Condous, G. Proposed technique to visualize and classify uterosacral ligament deep endometriosis with and without infiltration into parametrium or torus uterinus. Ultrasound Obstet. Gynecol. 2020, 55, 137-139. [CrossRef]

26. Leonardi, M.; Condous, G. A pictorial guide to the ultrasound identification and assessment of uterosacral ligaments in women with potential endometriosis. Australas. J. Ultrasound Med. 2019, 22, 157-164. [CrossRef]

27. Lima, R.; Abdalla-Ribeiro, H.; Nicola, A.L.; Eras, A.; Lobao, A.; Ribeiro, P.A. Endometriosis on the uterosacral ligament: A marker of ureteral involvement. Fertil. Steril. 2017, 107, 1348-1354. [CrossRef]

28. Bretón, S.A.; Carrasco, A.L.; Gutierrez, A.H.; González, R.R.; García, J.D.S. Complete loss of unilateral renal function secondary to endometriosis: A report of three cases. Eur. J. Obstet. Gynecol. Reprod. Boil. 2013, 171, 132-137. [CrossRef]

29. Nezhat, C.; Paka, C.; Gomaa, M.; Schipper, E. Silent Loss of Kidney Seconary to Ureteral Endometriosis. JSLS J. Soc. Laparoendosc. Surg. 2012, 16, 451-455. [CrossRef]

30. Berger, J.P.; Rhemrev, J.; Smeets, M.; Henneman, O.; English, J.; Jansen, F.W. Limited Added Value of Magnetic Resonance Imaging After Dynamic Transvaginal Ultrasound for Preoperative Staging of Endometriosis in Daily Practice: A Prospective Cohort Study. J. Ultrasound Med. 2018, 38, 989-996. [CrossRef]

31. Gutiérrez, A.H.; Spagnolo, E.; Hidalgo, P.; López, A.; Zapardiel, I.; Rodriguez, R.; Hernández, A. Magnetic resonance imaging versus transvaginal ultrasound for complete survey of the pelvic compartments among patients with deep infiltrating endometriosis. Int. J. Gynecol. Obstet. 2019, 146, 380-385. [CrossRef] [PubMed] 
32. Bazot, M.; Darai, E.; Hourani, R.; Thomassin, I.; Cortez, A.; Uzan, S.; Buy, J.-N. Deep Pelvic Endometriosis: MR Imaging for Diagnosis and Prediction of Extension of Disease. Radiology 2004, 232, 379-389. [CrossRef] [PubMed]

33. Medeiros, L.R.F.; Da Rosa, M.I.; Silva, B.R.; Reis, M.E.; Simon, C.S.; Dondossola, E.R.; Cunha-Filho, J.S. Accuracy of magnetic resonance in deeply infiltrating endometriosis: A systematic review and meta-analysis. Arch. Gynecol. Obstet. 2014, 291, 611-621. [CrossRef] [PubMed]

34. Nisenblat, V.; Farquhar, C.; Akoum, A.; Fraser, I.; Bossuyt, P.M. Non-invasive tests for the diagnosis of endometriosis. Cochrane Database Syst. Rev. 2012. [CrossRef]

35. Bazot, M.; Daraï, E. Diagnosis of deep endometriosis: Clinical examination, ultrasonography, magnetic resonance imaging, and other techniques. Fertil. Steril. 2017, 108, 886-894. [CrossRef]

36. Sillou, S.; Poirée, S.; Millischer, A.; Chapron, C.; Helenon, O. Urinary endometriosis: MR Imaging appearance with surgical and histological correlations. Diagn. Interv. Imaging 2015, 96, 373-381. [CrossRef]

37. Kinkel, K.; Frei, K.A.; Balleyguier, C.; Chapron, C. Diagnosis of endometriosis with imaging: A review. Eur. Radiol. 2005, 16, 285-298. [CrossRef]

38. Barra, F.; Scala, C.; Biscaldi, E.; Vellone, V.G.; Ceccaroni, M.; Terrone, C.; Ferrero, S. Ureteral endometriosis: A systematic review of epidemiology, pathogenesis, diagnosis, treatment, risk of malignant transformation and fertility. Hum. Reprod. Updat. 2018, 24, 710-730. [CrossRef]

39. Abreu-Gomez, J.; Udare, A.; Shanbhogue, K.P.; Schieda, N. Update on MR urography (MRU): Technique and clinical applications. Abdom. Radiol. 2019, 44, 3800-3810. [CrossRef]

40. Geng, J.-H.; Lee, Y.-C. Bladder Endometriosis. N. Engl. J. Med. 2019, 381, e43. [CrossRef]

41. Berlanda, N.; Somigliana, E.; Frattaruolo, M.P.; Buggio, L.; Dridi, D.; Vercellini, P. Surgery versus hormonal therapy for deep endometriosis: Is it a choice of the physician? Eur. J. Obstet. Gynecol. Reprod. Boil. 2017, 209, 67-71. [CrossRef] [PubMed]

42. Chapron, C.; Bourret, A.; Chopin, N.; Dousset, B.; Leconte, M.; Amsellem-Ouazana, D.; De Ziegler, D.; Borghese, B. Surgery for bladder endometriosis: Long-term results and concomitant management of associated posterior deep lesions. Hum. Reprod. 2010, 25, 884-889. [CrossRef] [PubMed]

43. Kołodziej, A.; Krajewski, W.; Dołowy, Ł.; Hirnle, L. Urinary Tract Endometriosis. Urol. J. 2015, 12, $2213-2217$. [PubMed]

44. Westney, O.L.; Amundsen, C.L.; McGuire, E.J. BLADDER ENDOMETRIOSIS: CONSERVATIVE MANAGEMENT. J. Urol. 2000, 163, 1814-1817. [CrossRef]

45. Fedele, L.; Bianchi, S.; Montefusco, S.; Frontino, G.; Carmignani, L. A gonadotropin-releasing hormone agonist versus a continuous oral contraceptive pill in the treatment of bladder endometriosis. Fertil. Steril. 2008, 90, 183-184. [CrossRef]

46. Fedele, L.; Bianchi, S.; Zanconato, G.; Bergamini, V.; Berlanda, N.; Carmignani, L. Long-term follow-up after conservative surgery for bladder endometriosis. Fertil. Steril. 2005, 83, 1729-1733. [CrossRef]

47. Reisenauer, C. Vesicovaginal fistulas: A gynecological experience in 41 cases at a German pelvic floor center. Arch. Gynecol. Obstet. 2015, 292, 245-253. [CrossRef]

48. Chapron, C.; Chiodo, I.; Leconte, M.; Amsellem-Ouazana, D.; Chopin, N.; Borghese, B.; Dousset, B. Severe ureteral endometriosis: The intrinsic type is not so rare after complete surgical exeresis of deep endometriotic lesions. Fertil. Steril. 2010, 93, 2115-2120. [CrossRef]

49. Soriano, D.; Schonman, R.; Nadu, A.; Lebovitz, O.; Schiff, E.; Seidman, D.S.; Goldenberg, M. Multidisciplinary Team Approach to Management of Severe Endometriosis Affecting the Ureter: Long-term Outcome Data and Treatment Algorithm. J. Minim. Invasive Gynecol. 2011, 18, 483-488. [CrossRef]

50. Frenna, V.; Santos, L.; Ohana, E.; Bailey, C.; Wattiez, A. Laparoscopic management of ureteral endometriosis: Our experience. J. Minim. Invasive Gynecol. 2007, 14, 169-171. [CrossRef]

51. Comiter, C.V. Endometriosis of the urinary tract. Urol. Clin. N. Am. 2002, 29, 625-635. [CrossRef]

52. Seracchioli, R.; Raimondo, D.; Di Donato, N.; Leonardi, D.; Spagnolo, E.; Paradisi, R.; Montanari, G.; Caprara, G.; Zannoni, L. Histological evaluation of ureteral involvement in women with deep infiltrating endometriosis: Analysis of a large series. Hum. Reprod. 2015, 30, 833-839. [CrossRef] [PubMed]

53. Freire, M.J.; Dinis, P.J.; Medeiros, R.; Sousa, L.; Águas, F.; Figueiredo, A. Deep Infiltrating Endometriosis-Urinary Tract Involvement and Predictive Factors for Major Surgery. Urology 2017, 108, 65-70. [CrossRef] [PubMed] 
54. Fernbach, S.K.; Maizels, M.; Conway, J.J. Ultrasound grading of hydronephrosis: Introduction to the system used by the society for fetal urology. Pediatr. Radiol. 1993, 23, 478-480. [CrossRef]

55. Gantt, P.A.; Hunt, J.B.; McDonough, P.G. Progestin reversal of ureteral endometriosis. Obstet. Gynecol. 1981, 57, 665-667.

56. Leonardi, M.; Condous, G. Redefining ureterolysis to mirror the skills of modern gynecologists. J. Minim. Invasive Gynecol. 2020. [CrossRef]

57. Ceccaroni, M.; Ceccarello, M.; Caleffi, G.; Clarizia, R.; Scarperi, S.; Pastorello, M.; Molinari, A.; Ruffo, G.; Cavalleri, S. Total Laparoscopic Ureteroneocystostomy for Ureteral Endometriosis: A Single-Center Experience of 160 Consecutive Patients. J. Minim. Invasive Gynecol. 2019, 26, 78-86. [CrossRef]

58. Pérez, M.P.-U.; Bazán, A.A.; Dorrego, J.M.A.; Hernandez, A.; De Francisco, M.G.; Hernandez, M.M.; De Santiago, J.; Barthel, J.D.L.P. Urinary Tract Endometriosis: Clinical, Diagnostic, and Therapeutic Aspects. Urology 2009, 73, 47-51. [CrossRef]

59. Dallas, K.B.; Rogo-Gupta, L.; Elliott, C.S. Urologic Injury and Fistula after Hysterectomy for Benign Indications. Obstet. Gynecol. 2019, 134, 241-249. [CrossRef]

(C) 2020 by the authors. Licensee MDPI, Basel, Switzerland. This article is an open access article distributed under the terms and conditions of the Creative Commons Attribution (CC BY) license (http://creativecommons.org/licenses/by/4.0/). 